\title{
Erratum to: Application of Virtual Reality Technology in Disaster Medicine
}

\author{
Yu-yu DUAN ${ }^{1}$, Jia-yao ZHANG ${ }^{2}$, Mao XIE², Xiao-bo FENG ${ }^{2}$, Song XU², Zhe-wei YE ${ }^{2}$ \\ ${ }^{I}$ The Clinical School of Chinese Medicine, Hubei University of Chinese Medicine, Wuhan 430065, China \\ ${ }^{2}$ Department of Orthopaedics, Union Hospital, Tongji Medical College, Huazhong University of Science and Technology, \\ Wuhan 430022, China
}

(C) The Author(s) 2020

\author{
Current Medical Science \\ https://link.springer.com/article/s11596-019-2093-4 \\ 39(5):690-694,2019
}

The article "Application of Virtual Reality Technology in Disaster Medicine”, written by Yu-yu DUAN, Jia-yao ZHANG, Mao XIE, Xiao-bo FENG, Song XU, Zhe-wei YE, was originally published electronically on the publisher's internet portal on October 2019 without open access. With the author(s)' decision to opt for Open Choice, the copyright of the article is changed to (C) The Author(s) 2020 and the article is forthwith distributed under a Creative Commons Attribution 4.0 International License (https://creativecommons.org/licenses/by/4.0/), which permits use, sharing, adaptation, distribution and reproduction in any medium or format, as long as you give appropriate credit to the original author(s) and the source, provide a link to the Creative Commons license, and indicate if changes were made.

The original article has been corrected.

Corresponding author: Zhe-wei YE 